\title{
Forced Degradation Studies of Drospirenone: Isolation and Characterization of Degradation Products
}

\author{
Shubhangi Bhaskarrao Sutar ${ }^{1, *}$, Veerendra Channabasappa Yeligar ${ }^{2}$, Sachinkumar Vasantrao Patil' \\ ${ }^{1}$ Department of Pharmaceutical Quality Assurance, Ashokrao Mane College of Pharmacy, Peth-Vadgaon Maharashtra, INDIA. \\ ${ }^{2}$ Krishna Institute of Pharmacy, KIMSDTU, Karad, Maharashtra, INDIA.
}

\begin{abstract}
Aim and Objectives: To remain safe for further processing or human consumption, study of stressed degradation for the identification of feasible degradants is required. The stability indicating high performance thin layer chromatographic method was developed with Camag HPTLC system. Materials and Methods: Silica C6OF $_{254}$ precoated TLC plates were used as stationary phase for separation of degradation products. The optimized mobile phase system consist of toluene: methanol: diethylamine (7:3:0.1) at $280 \mathrm{~nm}$. Results: From the mass details and IR, NMR interpretation, the plausible structure of alkaline degradation product of drospirenone could be $17 \alpha$ (3-hydroxy propyl)-6 $\beta, 7 \beta$, $15 \beta$, 16 $\beta$-dimethylene- $5 \beta$-androstane-3 $3,5,17 \beta$ triol and acidic degradation product of drospirenone could be 3-oxo-15 $\alpha, 16 \alpha$-dihydro-3'H-cyclopropa[15,16]-17 $\alpha$-pregna-4,6diene-21,17-carbolactone. Also in silico toxicity studies of the degradation products were performed to assess the toxicity profile of the products using Protox online sever. Conclusion: This analytical method can be considered as an alternative practical and inexpensive method for simple, accurate and efficient quantitative detection of drospirenone in the presence of its degraded products.
\end{abstract}

Key words: Drospirenone, Characterization, Forced degradation studies, in silico toxicity study, Degradation products of drospirenone.

\section{INTRODUCTION}

Chemically drospirenone (DROS) is $6 \beta, 7 \beta$, $15 \beta, 16 \beta$-dimethylene-3-oxo-17 $\alpha$-pregn-4-ene 21,17 carbolactone. DROS is a synthesized progestin that is an analog to spironolactone. It is present in number of birth control formulations. As such drospirenone has anti-mineralocorticoid properties, counteracts the estrogen - stimulated activity of the rennin - angiotensin - aldosterone system, and is not androgenic. ${ }^{1}$ Stability testing is done primarily to provide the evidence that the drug substance or the drug product maintains its essential features of quality, identity, purity and strength (within acceptable ranges) throughout the time in which, it is expected to remain safe for further processing or human consumption. ${ }^{2}$ The ICH Q1A guidelines established that stability-indicating method (SIAM) require for elucidating the inherent stability of the active substance by applying different stress conditions. Stressed degradation studies support for the identification of feasible degradants, the inherent stability of the drug molecules, possible degradation pathways and stability indicated analytical method validation..$^{3-5} \mathrm{~A}$ complete literature survey revealed that most widely high performance liquid chromatography (HPLC) techniques have been published for quantification and pharmacokinetic studies of DROS mostly in combination with ethinyl estradiol or other drugs in pharmaceutical formulations as well as biological fluids..$^{6-12}$ While, there is no analytical method accounted for isolation and characterization
Submission Date: 14-07-2020; Revision Date: 29-04-2021; Accepted Date: 09-08-2021

DOI: 10.5530/ijper.55.3s.177 Correspondence: Dr. Shubhangi B. Sutar Department of Pharmaceutical Quality Assurance, Ashokrao Mane College of Pharmacy, Peth -Vadgaon, Maharashtra, INDIA. Phone: +91-7276114156, Email - shubhangi.sutar28@ gmail.com

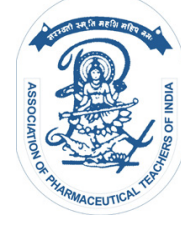

www.ijper.org 
of degradation products of DROS under various stressed conditions. In the present study, we attempted to develop a simple, accurate and precise method for the estimation of drospirenone in the presence of its degraded products and identification of drospirenone degradation products under different stress conditions through IR, NMR and MS characterization.

\section{MATERIALS AND METHODS}

\section{Instrumentation}

Microsyringe (Linomat (659.004) syringe, HamiltonBonaduz Schweiz, Camag,), Silica gel 60 F-254 aluminium plates (pre-coated) $(250 \mu \mathrm{m}$ thickness, $10 \times 10 \mathrm{~cm}$; Merck, Germany), Linomat 5 applicator (Camag, Switzerland), saturation pad (Camag, Muttenz, Switzerland), twin trough chamber $(20 \times 10 \mathrm{~cm}$; Camag, Muttenz, Switzerland), UV chamber (Camag, Switzerland), TLC scanner III (Camag, Muttenz, Switzerland), in this study winCATS version 1.4.0 software (Camag, Muttenz, Switzerland) were used. The FT-IR spectrum was recorded in $\mathrm{KBr}$ pellets on a Shimadzu FT-IR PC infrared spectrophotometer in the range as of 4000 to $400 \mathrm{~cm}^{-1}$. The ${ }^{1} \mathrm{H}$ NMR spectrums were recorded on a Bruker spectrometer $(400 \mathrm{MHz})$ using DCM as the solvent. Mass spectrometry was determined in the DI Shimadzu QP-2010 Plus analysis. Microsoft excel was as well used to treat data statistically.

\section{Reference standard substances and reagents}

Drospirenone was procured from swapanroop drugs and Pharmaceuticals (Aurangabad India) as a generous gift sample. The pharmaceutical form used in this study was Crisanta (Cipla, India) obtained from the local market as well labelled to contain $3 \mathrm{mg}$ of drospirenone per tablet. Toluene, Methanol, diethylamine, $\mathrm{NaOH}, \mathrm{HCl}, \mathrm{H}_{2} \mathrm{O}_{2}$, etc. all solvents as well as reagents used were of analytical grade.

\section{Selection of analytical wavelength for densitometric evaluations}

Std.stock solution was applied on TLC plate by means of CAMAG LINOMA-V automatic sample applicator, in order to determine the absorbance maxima. The plate was developed in twin-through glass chamber saturated by means of mobile phase for $10 \mathrm{~min}$. The plate was removed as well dried after chromatographic development. Bands on the TLC plate were scanned in the wavelength range of $200-800 \mathrm{~nm}$. Drospirenone showed absorbance and good resolution at $280 \mathrm{~nm}$ which is selected as analytic wavelength.

\section{Selection of mobile phase}

Appropriate dilutions of stock solutions were prepared and applied on TLC plates in the form of band (band size: $6 \mathrm{~mm}$ ) and the plates were run into different solvent system. Different mobile phase system consist of - toluene: methanol, toluene: methanol: chloroform, toluene: methanol: GAA, methanol: 1\% ammonium acetate solution, chloroform: dimethylamine were tried in different ratios in order to conclude best condition for the effectual separation. Amongst the different mobile phase combinations tested, toluene: methanol: diethylamine (7:3:0.1) was selected as it gives good resolution and peak symmetry for DROS. The $R_{f}$ value for drospirenone was found to be 0.69 as shown (Figure 1).

\section{Optimized chromatographic conditions}

The chromatographic separation were optimized at room temperature $\left(25 \pm 2^{\circ} \mathrm{C}\right)$ on stationary phase aluminium plates precoated with silica gel 60 , plate size $10 \mathrm{~cm} \times 10 \mathrm{~cm}$. Mobile phase toluene: methanol: diethylamine (7:3:0.1) were used. Sample applicator volume $0.6 \mu \mathrm{l}$, band size $6 \mathrm{~mm}$ and development chamber twinthrough glass chamber, $10 \mathrm{~cm} \times 10 \mathrm{~cm}$ with stainless steel lid were used. Wavelength $280 \mathrm{~nm}$ selected as analytical wavelength. (Table 1).

\section{Analysis of marketed formulation}

\section{Six samples were prepared and analyzed as follows}

Accurately weighed extent of tablet powder equivalent to about $3 \mathrm{mg}$ of DROS was transferred to $10 \mathrm{ml}$ volumetric flask, few $\mathrm{ml}$ of methanol was added as well as ultrasonicated for $10 \mathrm{~min}$, volume was subsequently made up to the mark with methanol. On the TLC plate bands of standard stock solution and bands of sample solution, $0.6 \mu 1$ were applied and the plate was developed and scanned under optimum chromatographic conditions. After scanning, the peak obtained for standard and sample bands were integrated. The amount

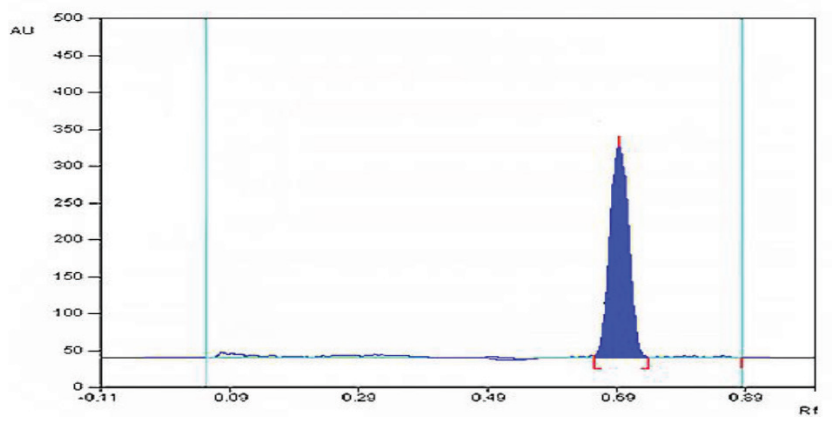

Figure 1: Typical densitogram of drospirenone ( $R_{f}$ Value: 0.69 ). 


\section{Table 1: Optimized Chromatographic conditions.}

\begin{tabular}{|c|c|}
\hline Stationary Phase & Aluminium plates precoated with silica gel 60 \\
\hline Mobile Phase & Toluene: Methanol: diethylamine $(7: 3: 0.1)$ \\
\hline Plate size & $10 \mathrm{~cm} \times 10 \mathrm{~cm}$ \\
\hline Mode of application & Band \\
\hline Band Size & $6 \mathrm{~mm}$ \\
\hline Sample applicator volume & $0.6 \mu \mathrm{l}$ \\
\hline Development Chamber & $\begin{array}{c}\text { Twin-through glass chamber, } 10 \mathrm{~cm} \times 10 \mathrm{~cm} \\
\text { with stainless steel lid. }\end{array}$ \\
\hline Saturation Time & $10 \mathrm{~min}$ \\
\hline Scanning Mode & Absorbance /Reflection \\
\hline Slit Dimensions & $5 \times 0.45 \mathrm{~mm}$ \\
\hline Scanning Wavelength & $280 \mathrm{~nm}$ \\
\hline
\end{tabular}

\begin{tabular}{|c|c|c|c|c|c|c|c|c|}
\hline \multicolumn{9}{|c|}{ Crisanta $3 \mathrm{mg}$} \\
\hline Sr. No. & $\begin{array}{l}\text { Weight of the } \\
\text { Tablet Powder } \\
\text { (mg) }\end{array}$ & Peak Area & $\begin{array}{l}\text { Amount } \\
\text { Found } \\
\text { Mg/tab }\end{array}$ & $\begin{array}{l}\text { \% Label } \\
\text { Claim }\end{array}$ & $\begin{array}{l}\text { Amount of } \\
\text { Drug Found }\end{array}$ & $\begin{array}{l}\% \text { Label } \\
\text { claim }\end{array}$ & S.D. & $\%$ RSD \\
\hline 1 & 162.87 & 4972.41 & 161.84 & 99.75 & \multirow{6}{*}{162.29} & \multirow{6}{*}{99.73} & \multirow{6}{*}{1.10} & \multirow{6}{*}{1.78} \\
\hline 2 & 163.10 & 4971.44 & 165.01 & 101.17 & & & & \\
\hline 3 & 162.20 & 4970.46 & 161.84 & 99.66 & & & & \\
\hline 4 & 162.01 & 4970.46 & 161.72 & 99.82 & & & & \\
\hline 5 & 163.03 & 4970.46 & 164.54 & 100.92 & & & & \\
\hline 6 & 162.92 & 4970.46 & 159.80 & 98.08 & & & & \\
\hline
\end{tabular}

of DROS (in $\mathrm{mg} /$ tablet) was calculated by comparing mean peak area of sample with that of standard. Result of analysis of tablet of formulation and its statistical evaluation are shown in (Table 2).

\section{Method Validation}

The method was validated in fulfilment of $\mathrm{ICH}$ guidelines. The subsequent parameters were used for validation of developed method.

\section{Linearity}

Linear relationship accompanied by peak area and drug concentration was evaluated over the concentration range expressed in ng band ${ }^{-1}$ by making six repeated measurements in the concentration range of 0.2 to $1.2 \mu$ l. Densitometric evaluations of the drug were performed at $280 \mathrm{~nm}$ (Figure 2). The standard calibration curve for drospirenone is shown in (Figure 3).

\section{Accuracy}

To ensure the accuracy of the planned method, recovery studies were carried out with standard addition method at $80,100,120 \%$ of the test concentration as per ICH guidelines.

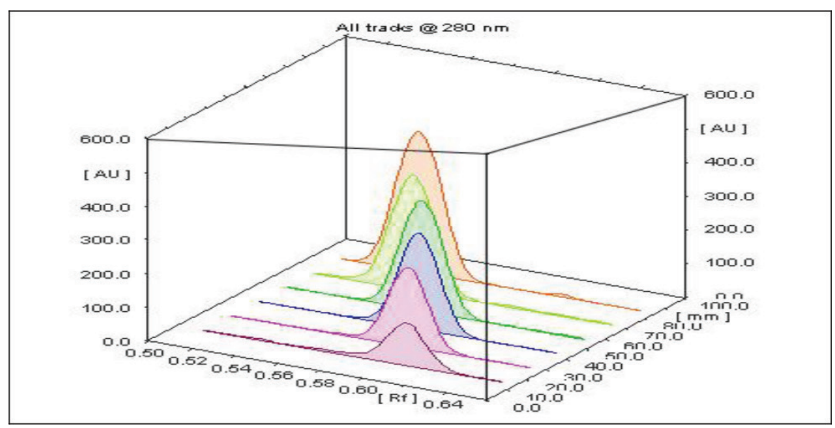

Figure 2: Overlay of drospirenone Linearity at $280 \mathrm{~nm}$.

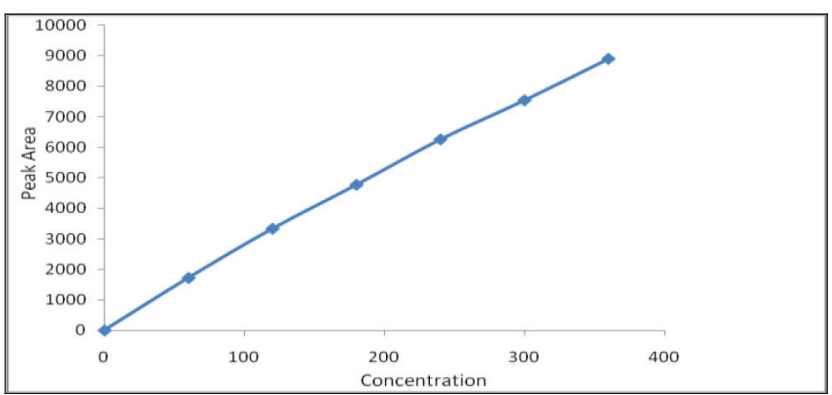

Figure 3: Calibration curve for drospirenone. 


\section{Precision}

Precision of the developed method was studied by performing repeatability as well as intermediate precision studies.

\section{Repeatability}

To verify the degree of repeatability of the method, suitable statistical evaluation was carried out. Six sample of the marketed tablets preparation were analyzed as per the procedure given under the analysis of the same. The standard deviation (S.D.), \% relative standard deviation (\% RSD) was calculated.

\section{Intermediate precision}

Precision (Intraday and Interday) was determined by analysing tablet sample solutions at different time intervals on the similar day and on three different days, respectively. Tablet sample solution was prepared as well as analyzed in the related manner as described in analysis of marketed formulation.

\section{Limit of detection and limit of Quantitation}

The LOD and LOQ were determined which is based on the standard deviation of response of the calibration curve.

\section{Robustness study}

The effect of intended variations in method parameters like mobile phase composition, mobile phase volume, spotting to development time and time as of development to scanning were evaluated in this study. The effect of these changes on both the $\mathrm{R}_{\mathrm{f}}$ values and peak areas was evaluated by calculating the relative standard deviations (RSD) for each parameter.

\section{Forced degradation studies of drospirenone}

For forced degradation studies, standard drug was subjected to variety of stress conditions like acidic, alkaline, oxidative, thermal and also neutral degradation.

\section{Acid induced degradation}

Acidic degradation involved exposing drug solution to the varying strengths of $\mathrm{HCl}(0.1 \mathrm{~N}, 0.5 \mathrm{~N}, 1.0 \mathrm{~N})$ at $80^{\circ} \mathrm{C}$ for $1 \mathrm{hr}$. The mixture were refluxed at $80^{\circ} \mathrm{C}$ for $1 \mathrm{hr}$, cooled and neutralised suitably. Before HPTLC analysis, the acidic stress solutions were diluted up to $300 \mu \mathrm{g} / \mathrm{ml}$ with methanol and developed the plate using optimized chromatographic conditions.

\section{Alkali induced degradation}

Alkali induced degradation involved exposing drug solution to the varying strengths of $\mathrm{NaOH}(0.1 \mathrm{~N}, 0.5 \mathrm{~N}$, $1.0 \mathrm{~N})$ at $60^{\circ} \mathrm{C}$ for $30 \mathrm{~min}$. The mixtures were refluxed at $60^{\circ} \mathrm{C}$ for $30 \mathrm{~min}$ cooled and neutralised suitably. Before HPTLC analysis, the alkaline stress solutions were diluted up to $300 \mu \mathrm{g} / \mathrm{ml}$ in methanol and developed the plate using optimized chromatographic conditions.

\section{Hydrogen peroxide induced (oxidative) degradation}

$3 \mathrm{ml}$ of $3 \% \mathrm{H}_{2} \mathrm{O}_{2}$ was added to volumetric flask containing weighed quantity of drug. The above reaction mixture was heated in precession water bath at $80^{\circ} \mathrm{C}$ for $1 \mathrm{hr}$. The reaction mixture was well kept in dark to avoid photo-oxidation effect.

\section{Neutral degradation}

For neutral condition, drug dissolved in water and heated at $80^{\circ} \mathrm{C}$ for $1 \mathrm{hr}$. The neutral stress solution was cooled and diluted to $300 \mu \mathrm{g} / \mathrm{ml}$ in methanol and developed the plate using optimized chromatographic conditions.

\section{Isolation of alkaline and acidic degradation products by using HPTLC method}

A precisely weighed quantity of $3 \mathrm{mg}$ of drug was dissolved in smaller quantity of methanol. Subsequently, $3 \mathrm{ml}$ of $1 \mathrm{~N}$ Sodium hydroxide was added and the resultant solution was refluxed in round bottom flask (RBF) on water bath (temperature controlled precision) at $60^{\circ} \mathrm{C}$ for $30 \mathrm{~min}$. Similarly precisely weighed quantity of $3 \mathrm{mg}$ of drospirenone was dissolved in smaller quantity of methanol. Subsequently, $3 \mathrm{ml}$ of $1 \mathrm{~N} \mathrm{HCl}$ was added and the resultant solution was refluxed in RBF on temperature controlled precision water bath at $80^{\circ} \mathrm{C}$ for $1 \mathrm{hr}$. The RBF was removed and allowed to cool and volume was made up to $10 \mathrm{ml}$ with methanol. The alkaline as well as acidic degradation of drospirenone was confirmed by means of newly developed method, where the major degradants formed in stressed state was isolated all through preparative HPTLC technique.

For isolation of degradation product, after development of the plate this plate was observed under the UV chamber and the band of standard and degradation product were marked and further scraped and exacted with methanol. The structures of degradant products were determined by IR, NMR, MS studies.

\section{In silico toxicity study of drospirenone degradation products}

In silico toxicity studies of the degradation products were performed to assess the toxicity profile of the products. In silico toxicity was accessed through the Protox II (http://tox.charite.de/protox_II/). Protox II is based a 33 models for the prediction of various toxicity 
as acute toxicity, cytotoxicity, hepatotoxicity, carcinogenicity, immunotoxicity, Mutagenicity.

\section{RESULTS AND DISCUSSION}

\section{Method Validation}

The proposed method was validated by studying parameters as accuracy, linearity, precision, limit of detection (LOD), limit of quantitation (LOQ) and robustness. ${ }^{13}$ Peak areas were found to consist of better linear relationship with concentration than peak heights. For DROS, $R^{2}$ was found to be 0.998 , calibration graph were construct in the concentration range of $60-360 \mathrm{ng} \mathrm{band}^{-1}$. The correlation coefficient, $y$ intercept and slope of the regression line was calculated and present in the (Table 3). At all the three levels percentage recovery was found to be satisfactory (Table 4). The \% recovery was found between $100.26 \%$ and $100.55 \%$. Repeatability as well as intermediate precision of the developed method were expressed in terms of relative standard deviation (RSD). The coefficients of variation for repeatability, inter-day and intra-day precision of the method was found to be less than 2\% (Table 5). The standard deviation of $y$-intercept and slope of the calibration curves were used to calculate the LOD and LOQ. (LOD (ng/band) 5.38 and LOQ (ng/band) 16.32).

\begin{tabular}{|c|c|c|}
\hline \multicolumn{3}{|c|}{ Table 3: Linearity study in physical mixture. } \\
\hline Sr. No. & Concentration (ng/band) & Peak Area* $^{*}$ \\
\hline 1 & 0 & 0 \\
\hline 2 & 60 & 1719.13 \\
\hline 3 & 120 & 3330.76 \\
\hline 4 & 180 & 4770.46 \\
\hline 5 & 240 & 6259.24 \\
\hline 6 & 300 & 7540.18 \\
\hline 7 & 360 & 8899.93 \\
\hline
\end{tabular}

$(Y=1027.179+19.43 \times)\left(r^{2}=0.998\right)$.

\section{Forced degradation studies}

A minimal of three samples were generated for each stress condition, viz., the blank subjected to stress in the similar mode as the drug, zero time sample containing the drug stored under normal conditions, and the drug solution subjected to stress treatment. This gave the factual assessment of the amount of degradation of the drug molecule. The peak purity analysis was performed to conclude the percentage degradation along with total loss of the API during the formation of forced degradants. The drospirenone was found to be labile to acidic degradation showing degradation peaks at $\mathrm{R}_{f}$ 0.53 (Figure 4A) and highly labile to alkaline as comparative to acidic degradation showing degradation peaks at $\mathrm{R}_{f} 0.22,0.35,0.38$ and majorly 0.51 (Figure $4 \mathrm{~B}$ ). The drug was found to be labile towards oxidative degradation showing degradation peaks at $\mathrm{R}_{f} 0.48$ and 0.57 (Figure 4C) and no major degradation in neutral conditions, showing degradation peaks at $R_{f} 0.57$ (Figure 4D). Table 6 shows summary of degradation of drospirenone in different stress conditions.

\section{Characterization of degradation product of drospirenone}

\section{Mass (MS) study}

MS study was employed to obtain molecular weight as well fragmentation information of degradation products and it helps to structural information of degradation products. Alkali degradation shows generation of one degradation product. The MS spectrum of degraded drospirenone is shown in (Figure 5A). According to the $\mathrm{m} / \mathrm{z}$ values and fragmentation pattern, the possible structure for alkaline degradation product was proposed as shown in (Table 7). Acidic degradation shows generation of one degradation product. The MS spectrum of degraded drospirenone is shown in (Figure 6A). According to the $\mathrm{m} / \mathrm{z}$ values with fragmentation

\begin{tabular}{|c|c|c|c|c|c|c|c|}
\hline Sr. No. & $\begin{array}{l}\text { Level of } \\
\text { Recovery }\end{array}$ & $\begin{array}{c}\text { Actual } \\
\text { Concentration level }\end{array}$ & $\begin{array}{l}\text { Amount of } \\
\text { Drug present } \\
\text { ng/band }\end{array}$ & $\begin{array}{l}\text { Amount of Drug } \\
\text { Recovered (ng/ } \\
\text { band) }\end{array}$ & \% Recovery & $\begin{array}{c}\% \text { Mean } \\
\text { Recovery }\end{array}$ & $\%$ RSD \\
\hline \multirow{3}{*}{1} & \multirow{3}{*}{80} & \multirow{3}{*}{$2.4 \mathrm{mg}$} & 144 & 145.23 & 100.85 & \multirow{3}{*}{100.55} & \multirow{3}{*}{0.367} \\
\hline & & & 144 & 144.98 & 100.68 & & \\
\hline & & & 144 & 144.20 & 100.13 & & \\
\hline \multirow{3}{*}{2} & \multirow{3}{*}{100} & \multirow{3}{*}{$3 \mathrm{mg}$} & 180 & 180.46 & 100.25 & \multirow{3}{*}{100.29} & \multirow{3}{*}{0.182} \\
\hline & & & 180 & 180.24 & 100.13 & & \\
\hline & & & 180 & 180.89 & 100.49 & & \\
\hline \multirow{3}{*}{3} & \multirow{3}{*}{120} & \multirow{3}{*}{$3.6 \mathrm{mg}$} & 216 & 216.21 & 100.09 & \multirow{3}{*}{100.26} & \multirow{3}{*}{0.184} \\
\hline & & & 216 & 216.54 & 100.25 & & \\
\hline & & & 216 & 217.01 & 100.46 & & \\
\hline
\end{tabular}




\begin{tabular}{|c|c|c|c|}
\hline Precision parameters & $\%$ Label claim* & S.D. & \%RSD \\
\hline Repeatability & 99.10 & 1.01 & 1.019 \\
\hline Intraday precision & 100.05 & 1.81 & 1.80 \\
\hline Interday precision & 99.40 & 1.05 & 1.05 \\
\hline
\end{tabular}

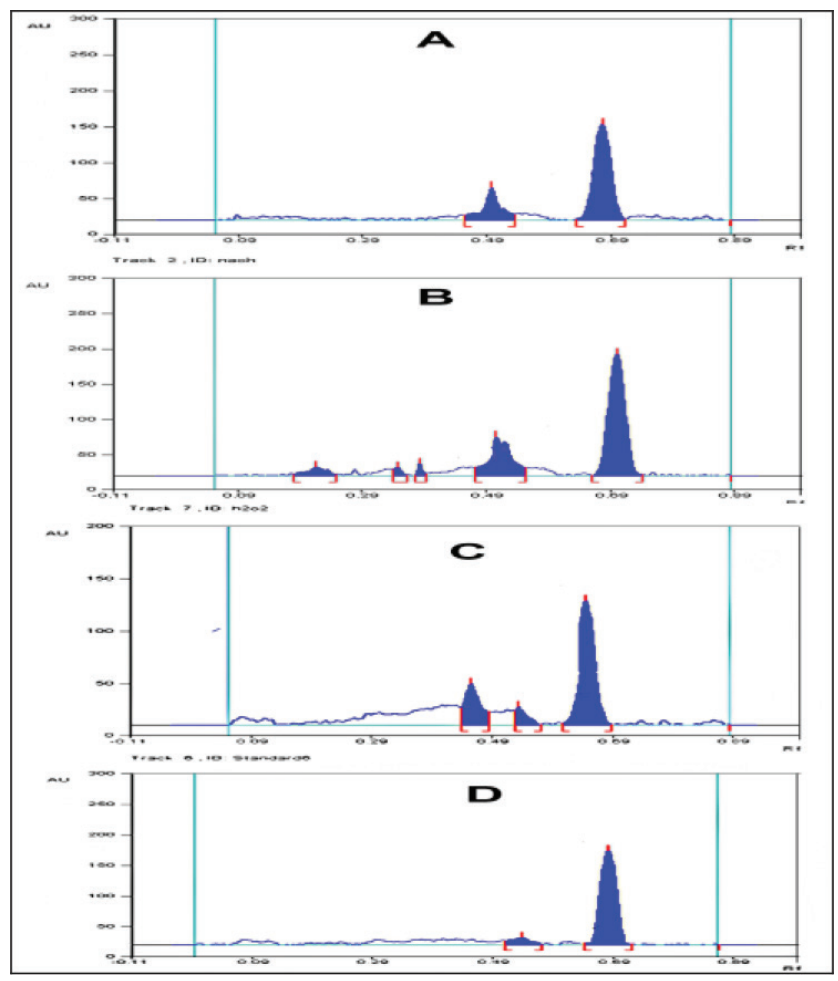

Figure 4: (A) Densitogram of $0.1 \mathrm{~N} \mathrm{HCl}$ stressed drospirenone after $1 \mathrm{hr}$ heating at $80^{\circ} \mathrm{C}$. (B) Densitogram of $0.1 \mathrm{~N} \mathrm{NaOH}$ stressed drospirenone after $30 \mathrm{~min}$ heating at $60^{\circ} \mathrm{C}$.

(C) Densitogram of $3 \% \mathrm{H}_{2} \mathrm{O}_{2}$ treated drospirenone after $1 \mathrm{hr}$ heating at $80^{\circ} \mathrm{C}$. (D) Densitogram of drospirenone after $1 \mathrm{hr}$ heating at $80^{\circ} \mathrm{C}$ in DW.

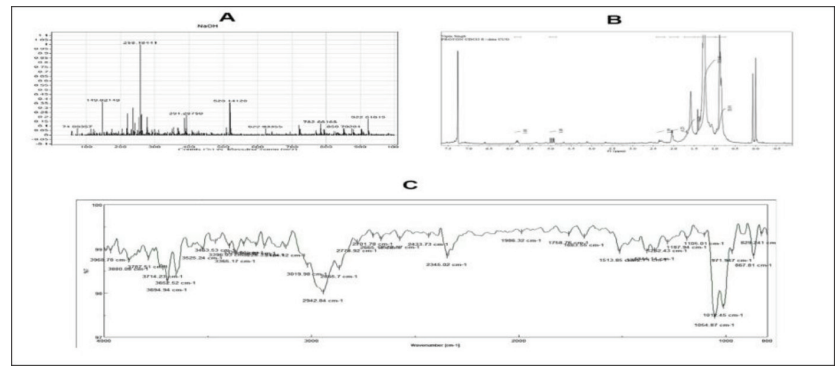

Figure 5: (A) Representation of MS spectrum of alkaline degradation product. (B) Representation of NMR spectrum of alkaline degradation product. (C) Representation of IR spectrum of alkaline degradation product of drospirenone.

\begin{tabular}{|c|c|c|}
\hline \multicolumn{3}{|c|}{$\begin{array}{c}\text { Interpretation of MS spectrum of alkaline degradation } \\
\text { product }\end{array}$} \\
\hline Sr. No. & $M+1$ & Molecular Fragments \\
\hline 1. & 391.28 & \\
\hline 2. & 74 & \\
\hline \multicolumn{3}{|c|}{$\begin{array}{l}\text { Interpretation of NMR spectrum of alkaline degradation } \\
\text { Product }\end{array}$} \\
\hline Sr. No. & Peak & $\delta$ ppm \\
\hline 1. & a & $7.54(\mathrm{~s}, 3 \mathrm{H}) \mathrm{OH}$ ( steroid) \\
\hline 2. & b & $4.5(36 \mathrm{H}) \mathrm{CH}_{3}$ \\
\hline 3. & c & $0.5-2.0 \mathrm{CH}$ steroids $\mathrm{CH}$ \\
\hline \multicolumn{3}{|c|}{$\begin{array}{c}\text { Interpretation of IR spectrum of alkaline degradation } \\
\text { Product }\end{array}$} \\
\hline Sr. No. & Range $\left(\mathrm{cm}^{-1}\right)$ & Indication \\
\hline 1. & 2942.84 & OH stretching \\
\hline 2. & 2865.68 & CH stretching (Alkane) \\
\hline
\end{tabular}

\begin{tabular}{|c|c|c|c|}
\multicolumn{4}{|c|}{ Table 6: Summary of degradation of drospirenone in } \\
stress conditions. \\
\hline $\begin{array}{c}\text { Stress } \\
\text { Condition }\end{array}$ & $\begin{array}{c}\text { Exposure } \\
\text { Condition }\end{array}$ & $\begin{array}{c}\text { Percentage } \\
\text { Degradation }\end{array}$ & $\begin{array}{c}\text { Peak } \\
\text { Purity }\end{array}$ \\
\hline Alkaline & $\begin{array}{c}0.1 \mathrm{~N} \mathrm{NaOH}, 60^{\circ} \mathrm{C} \text { for } \\
30 \mathrm{~min}\end{array}$ & 43.8 & 999.771 \\
\hline Acid & $\begin{array}{c}0.1 \mathrm{~N} \mathrm{HCl}, 80^{\circ} \mathrm{C} \text { for } \\
1 \mathrm{hr}\end{array}$ & 16.6 & 999.658 \\
\hline Neutral & $\begin{array}{c}\text { Solid drug in } \mathrm{DW} \\
80^{\circ} \mathrm{C} \text { for } 1 \mathrm{hr}\end{array}$ & 4.23 & 995.357 \\
\hline \multirow{2}{*}{ Oxidative } & $\begin{array}{c}1 \% \mathrm{H}_{2} \mathrm{O}_{2}, 80^{\circ} \mathrm{C} \text { for } \\
1 \mathrm{hr}\end{array}$ & 15.23 & 999.201 \\
\cline { 2 - 4 } & $\begin{array}{c}3 \% \mathrm{H}_{2} \mathrm{O}_{2}, 80^{\circ} \mathrm{C} \text { for } \\
1 \mathrm{hr}\end{array}$ & 26.06 & 999.211 \\
\hline
\end{tabular}

*Peak purity values in the range of 990-1000 indicates homogeneous analyte peak

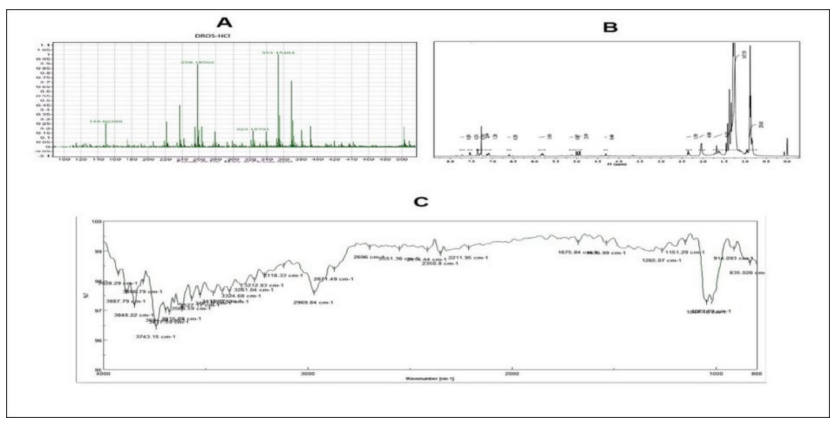

Figure 6: (A) Representation of MS spectrum of acidic degradation product (B) Representation of NMR spectrum of acidic degradation product (C) Representation of IR spectrum of acidic degradation product of drospirenone. 
pattern, the possible structure for acidic degradation product was proposed as shown in (Table 8).

NMR study: ${ }^{1 \mathrm{H}} \mathrm{NMR}$ was recorded at $500 \mathrm{MHz}$ and chemical shifts are derived from TMS peak at $\delta=0.00 \mathrm{pm}$. Extraction procedure: To the aqua solution DCM $(10 \mathrm{~mL})$ was added and extracted by using separating funnel. The layers were separated, and the aqueous layer was again extracted with DCM $(2 \times 10 \mathrm{~mL})$, combined organic layer were washed by brine $(20 \mathrm{~mL})$, dried over anhydrous $\mathrm{Na}_{2} \mathrm{SO}_{4}$. Solvent was evaporated under reduced pressure in rota evaporator to get the desired compound. NMR and IR spectrum of alkaline degraded DROS are shown in (Figure 5B and 5C) respectively. Band interpretation data shown in (Table 9) as well as NMR and IR spectra of acidic degraded drug are shown in (Figure 6B and 6C) respectively.

The MS value for alkaline degradation product is $\mathrm{m} / \mathrm{z}$ 391.28. The NMR spectrum showed the following signals: peak a:(s, $3 \mathrm{H}) \mathrm{OH}$ (steroid) appeared at $7.54 \delta \mathrm{ppm}$, peak $\mathrm{b}:(36 \mathrm{H}) \mathrm{CH}_{3}$ appeared at $4.5 \delta \mathrm{ppm}$, peak $\mathrm{C}: \mathrm{CH}$ steroids $\mathrm{CH}$ appeared at 0.5-2.0 $\delta \mathrm{ppm}$. The IR spectra showed $\mathrm{OH}$ stretching appeared at $2942.84 \mathrm{~cm}^{-1}$ and $\mathrm{CH}$ stretching (Alkane) appeared at $2865.68 \mathrm{~cm}^{-1}$. From the mass details and facts given above, the plausible structure of alkaline degradation

\begin{tabular}{|c|c|c|}
\hline \multicolumn{3}{|c|}{$\begin{array}{c}\text { Interpretation of MS spectrum of acidic degradation } \\
\text { product }\end{array}$} \\
\hline Sr. No. & $M+1$ & Molecular Fragments \\
\hline 1. & 353.14 & \\
\hline 2. & 323.18 & \\
\hline \multicolumn{3}{|c|}{$\begin{array}{c}\text { Interpretation of NMR spectrum of acidic degradation } \\
\text { product }\end{array}$} \\
\hline Sr. No. & Peak & d ppm \\
\hline 1. & a. & $4.8(36 \mathrm{H}) \mathrm{CH}_{3}$ \\
\hline 2. & b. & 0.5-2.5 $\mathrm{CH}$ steroids $\mathrm{CH}$ \\
\hline \multicolumn{3}{|c|}{ Interpretation of IR spectrum of Degradation Product } \\
\hline Sr. No. & Range $\left(\mathrm{cm}^{-1}\right)$ & $\delta$ ppm \\
\hline 1. & 1675 & $\mathrm{C}=\mathrm{O}$ stretching \\
\hline 2. & 2969 & $\mathrm{CH}$ stretching (Alkane) \\
\hline 3. & 1014 & C-O stretching \\
\hline
\end{tabular}

\begin{tabular}{|c|c|c|c|c|c|c|}
\hline 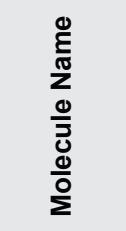 & 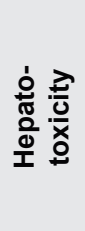 & 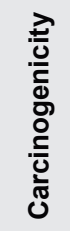 & 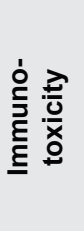 & 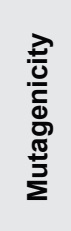 & $\begin{array}{l}\frac{\vec{J}}{0} \\
\frac{0}{x} \\
\text { to } \\
\text { Jे }\end{array}$ & 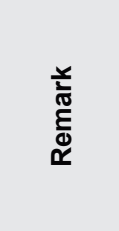 \\
\hline $\begin{array}{c}\text { DROS+ } \\
\mathrm{NaOH}\end{array}$ & 0.8 & 0.84 & 0.86 & 0.74 & 0.87 & $\begin{array}{l}\text { Immuno } \\
\text { toxic }\end{array}$ \\
\hline $\begin{array}{c}\text { DROS+ } \\
\text { HCl }\end{array}$ & 0.6 & 0.51 & 0.93 & 0.94 & 0.64 & $\begin{array}{c}\text { Immuno } \\
\text { toxic }\end{array}$ \\
\hline
\end{tabular}

product could be $17 \alpha$ (3-hydroxypropyl)- $6 \beta, 7 \beta, 15 \beta$, $16 \beta$-dimethylene- $5 \beta$-androstane- $3 \beta, 5,17 \beta$ triol..$^{14,15}$ The MS value for acidic degradation product is $\mathrm{m} / \mathrm{z} 353.14$. The NMR spectrum showed the following signals: peak a: $(36 \mathrm{H}) \mathrm{CH}_{3}$ appeared at $4.8 \delta \mathrm{ppm}$, peak c: $\mathrm{CH}$ steroids $\mathrm{CH}$ appeared at 0.5-2.0 $\delta \mathrm{ppm}$. The IR spectra showed $\mathrm{C}=\mathrm{O}$ stretching appeared at $1675 \mathrm{~cm}^{-1}$ and $\mathrm{CH}$ stretching (Alkane) appeared at $2969 \mathrm{~cm}^{-1}$. From the mass details and facts given above, the plausible structure of acidic degradation product could be $17 \alpha$ (3-hydroxypropyl)-6 $\beta, 7 \beta, 15 \beta, 16 \beta$-dimethylene-5 $\beta$ androstane- $3 \beta, 5,17 \beta$ triol.

\section{In silico toxicity study of drospirenone degradation products}

Toxicity prediction revealed both degradation products of drospirenone showed only immunotoxic and endpoints as shown in (Table 9).

\section{CONCLUSION}

The degradation behaviour of drospirenone under acid, base and neutral, oxidative-as per guidelines was studied. We successfully identify degradation products under acidic and alkaline stress conditions through IR, NMR and MS characterization. Additionally in silico toxicity studies of the degradation products were performed to assess the toxicity profile of the products using protox online sever. Hence, this analytical method can be considered as an alternative practical and inexpensive method for simple, accurate and efficient quantitative detection of drospirenone in the presence of its degraded products.

\section{ACKNOWLEDGEMENT}

The author would like to acknowledge the Ashokrao Mane College of Pharmacy, Peth-Vadgaon, Kolhapur, Maharashtra, India. 


\section{CONFLICT OF INTEREST}

The authors declare no conflict of interest.

\section{ABBREVIATIONS}

DROS: Drospirenone; ICH: International conference on harmonization; TLC: Thin layer chromatography; HPTLC: High performance thin layer chromatography; NMR: Nuclear magnetic resonance; IR: Infrared spectroscopy; RSD: Relative standard deviation; LOD: limit of detection; LOQ: limit of quantitation.

\section{REFERENCES}

1. Souri E, Mohammadzadeh SM, Tehrani MB. A stability indicating HPLC method for the determination of drospirenone in pharmaceutical dosage forms. Res J Pharm Biol Chem Sci. 2014;5(6):1-6.

2. Singh $R$, Urrehman $Z$. Current trend in forced degradation study for pharmaceutical products development. J Pharm Educ Res. 2012;3(1):54-63.

3. $\mathrm{ICH}$. Validation of analytical procedures: text and methodology. International Conference, Geneva, Switzerland.2005. Vol. Q2. (p. R1).

4. $\mathrm{ICH}$ [guidelines:Q1A. (p. R2)]. Stability testing of new drug substances and products. 2nd revision, International Conference on Harmonization.

5. Bakshi M, Singh S. Development of validated stability-indicating assay methods--critical review. J Pharm Biomed Anal. 2002;28(6):1011-40. doi: 10.1016/s0731-7085(02)00047-x, PMID 12049968

6. Pradad GR, Srinivas BP, Ramana MV. Validated RP-HPLC method for the estimation of drospirenone in formulation. Int $\mathrm{J}$ Res Pharm Biomed Sci. 2011;2:1341-5.
7. Silva VB, Galdos AAG, Mothe CMA, Pallastrelli MB, Prado MSA, Singh AK, Kedor-Hackmann ERM, Santoro MIRM. Simultaneous determination of ethinyl estradiol and drospirenone in oral contraceptive by high performance liquid chromatography. Braz J Pharm Sci. 2013;49(3):521-8. doi: 10.1590/ S1984-82502013000300013.

8. Babu NB, Raju RR. Simultaneous analysis and validation of risperidone and drospirenone drugs in pharmaceutical dosage form. Int J Res Pharm Biomed Sci. 2011;2:1638-42

9. Patel RC, Rathod DK, Rajesh KS, Patel VS. RP-HPLC method development and validation for estimation of drospirenone and ethinyl estradiol in bulk and combined dosage form. Pharmagene. 2013;1:15-20.

10. Li J, Ren J, Sun W. A comparative systematic review of Yasmin (drospirenone pill) versus standard treatment options for symptoms of polycystic ovary syndrome. Eur J Obstet Gynecol Reprod Biol. 2017;210:13-21. doi: 10.1016/j. ejogrb.2016.11.013, PMID 27923166.

11. Talath S, Dhaneshwar S. A simple and rapid validated stability indicating HPLC method for the determination of drospirenone in a pharmaceutical product. Indo Am J Pharm Res. 2017:7401-10.

12. Bhusari VK, Dhaneshwar SR. Validated HPTLC method for simultaneous estimation of ethinyl estradiol and drospirenone in bulk drug and formulation. Rev Anal Chem. 2012;31(2):123-9. doi: 10.1515/revac-2011-0037.

13. Jain D, Basniwal PK. Forced degradation and impurity profiling: recent trends in analytical perspectives. J Pharm Biomed Anal. 2013;86:11-35. doi: 10.1016/j.jpba.2013.07.013, PMID 23969330.

14. Trabelsi H, Hassen IE, Bouabdallah S, Bouzouita K, Safta F. Stability indicating LC method for the determination of pipamperone. J Pharm Biomed Anal. 2005;39(5):914-9. doi: 10.1016/j.jpba.2005.05.031, PMID 16040223.

15. 15. Dorman DE, Lornez LJ, Occolowitz JL, Spangle LA, Collins MW, Bashore FN, Baertschi SW. Isolation and structure elucidation of the major degradation products of cefaclor in the solid state. J Pharm Sci. 1997;86:526-39.

\section{PICTORIAL ABSTRACT}

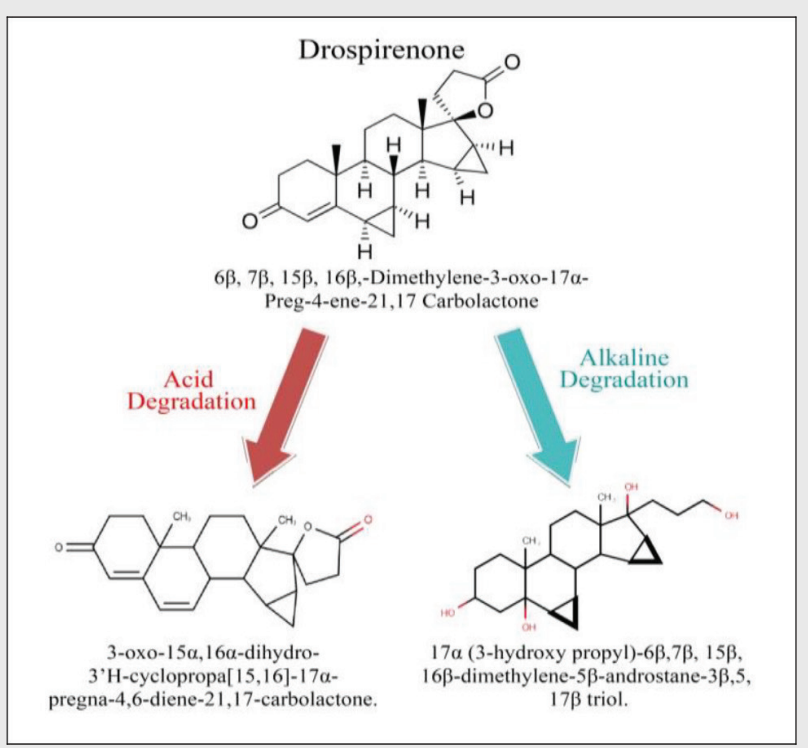

SUMMARY

Drospirenone was found to be degrading in alkaline, acidic and oxidative conditions. Degradation in alkaline condition was more as compared to oxidative and acidic stress conditions. The method was resolving the peak of degradation products from the peak of DROS. Further the characterisation by using IR, NMR, MS were carried out for acidic and alkaline degradation products of DROS. From the mass details and IR, NMR interpretation, the plausible structure of alkaline degradation product of DROS could be $17 \alpha$ (3-hydroxy propyl)-6 $\beta, 7 \beta, 15 \beta$, $16 \beta$-dimethylene- $5 \beta$-androstane- $3 \beta, 5,17 \beta$ triol and acidic degradation product of DROS could be 3-oxo$15 \alpha, 16 a$-dihydro-3'H-cyclopropa [15, 16]-17a-pregna4,6-diene-21,17-carbolactone. In silico toxicity studies of the degradation products was performed to assess the toxicity profile of the products by using Protox online server. Toxicity prediction revealed both degradation products of DROS showed only Immunotoxic. 


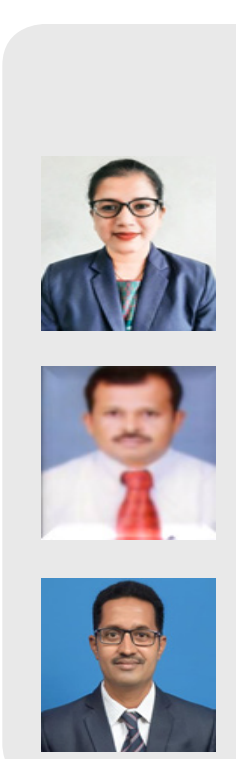

\section{About Authors}

Dr.Shubhangi B. Sutar, Associate Professor,Pharmaceutical Quality Assurance Department, Ashokrao Mane College of Pharmacy,Peth-Vadgaon,She is having more than 15 years of teaching and research experience. She has published 15 research papers in International and National journals and presented her research work in several national and international conferences.

Dr. Veerendra C.Yeligar, Professor, Krishna institute of Pharmacy KIMS DTU, Karad. He is having more than 25 years of teaching and research experience. He has published 42 research papers in International and National journals.

Dr. Sachinkumar V. Patil, Principal, Ashokrao Mane College of Pharmacy,Peth-Vadgaon, He is having more than 25 years of teaching and research experience. He has published 35 research papers in International and National journals and presented his research work in several national and international conferences.

Cite this article: Sutar SB, Yeligar VC, Patil SV. Forced Degradation Studies of Drospirenone: Isolation and Characterization of Degradation Products. Indian $\mathrm{J}$ of Pharmaceutical Education and Research. $2021 ; 55(3 s): s 700-s 708$. 